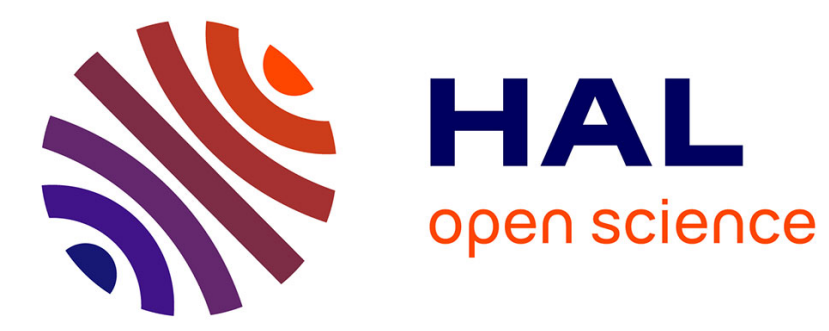

\title{
The Efficiency of Training and Hiring with Intra firm Bargaining
}

\author{
Fabien Tripier
}

\section{To cite this version:}

Fabien Tripier. The Efficiency of Training and Hiring with Intra firm Bargaining. 2010. hal-00449625

\section{HAL Id: hal-00449625 \\ https://hal.science/hal-00449625}

Preprint submitted on 22 Jan 2010

HAL is a multi-disciplinary open access archive for the deposit and dissemination of scientific research documents, whether they are published or not. The documents may come from teaching and research institutions in France or abroad, or from public or private research centers.
L'archive ouverte pluridisciplinaire HAL, est destinée au dépôt et à la diffusion de documents scientifiques de niveau recherche, publiés ou non, émanant des établissements d'enseignement et de recherche français ou étrangers, des laboratoires publics ou privés. 
EA 4272

\section{The Efficiency of Training and Hiring with Intrafirm Bargaining}

\section{Fabien TRIPIER*}

2010/04

* LEMNA - Université de Nantes

Laboratoire d'Economie et de Management Nantes-Atlantique Université de Nantes

Chemin de la Censive du Tertre - BP 52231

44322 Nantes cedex 3 - France

www.univ-nantes.fr/iemn-iae/recherche

Tél. +33 (0)2 40141717 - Fax +33 (0)2 40141749 


\title{
The Efficiency of Training and Hiring with Intrafirm
}

\section{Bargaining}

\author{
Fabien Tripier
}

January 10, 2010

\begin{abstract}
In a matching and intrafirm bargaining economy with constant return to scale production and matching technologies, large firms hire and train workers efficiently. The efficiency of the competitive economy relies on the ability of large firm to take into account the consequences of training on the wages bargained inside the firm. This intrafirm bargaining process solves the hold-up problem that is associated with training costs that would otherwise lead to inefficient decisions of hiring and training.
\end{abstract}

Keywords: Training; Matching; Bargaining; Efficiency

JEL Classification: J24; J31; C78 


\section{Introduction}

Imperfections in the labor market result in inefficiencies in decisions made by firms and workers that call for public intervention and labor market regulations. Against this background, training decisions have been widely studied. Training is a key determinant of labor market outcomes and is affected strongly by labor market imperfections, which give rise to hold-up phenomenon and externalities ${ }^{1}$. To link the training decisions with the unemployment issue, the canonical matching model of the labor market has been extended to study training decisions, firstly by Mortensen (2000), and later by Higashi (2002), Boone and de Mooij (2003), Moen and Rosen (2004), Rosholm and Svarer (2004), Chéron (2005), Shintoyo (2007), Hungerbühler (2007), Chéron et al. (2008), and Jansen (2009). These models share the special assumption that a firm is composed of a single worker, which rules out all the mechanisms that operate within the firm, such as the intrafirm bargaining process for the setting of wages that was proposed by Stole and Zwiebel (1996a, 1996b). In large firms, given that wage bargaining is internal to the firm, the firm takes into account the consequences of its organizational choices on wages. Herein, I analyze the normative implications of intrafirm bargaining on hiring and training decisions, which is absent by construction in the previously cited models of matching and training, where firms comprise only a single job.

The implications of intrafirm bargaining for hiring decisions have already been studied by Smith (1999), Cahuc and Wasmer (2001), Cahuc et al. (2008), and Mortensen (2009) in different versions of the matching model with large firms of Pissarides (2000). They show that intrafirm bargaining has strong normative and positive implications for equilibrium unemployment. In particular, the traditional condition of $\operatorname{Hosios}^{2}$ (1990) is generally not sufficient to ensure the efficiency of the

\footnotetext{
${ }^{1}$ Ericson (2005) provides an excellent survey of the economics of training. The issue of hold-up is studied by Malcomson (1997), and the pecuniary and poaching externalities by Acemoglu (1997) and Acemgolu and Pischke (1998).

${ }^{2}$ This condition states that the matching externalities are exactly internalized in the bargaining process for setting wages if the bargaining power of firms (respectively workers) is equal to the elasticity of the matching function with
} 
decentralized economy. However, none of these articles deals with the training issue. In light of this, I here develop an original model to analyze the training decision in a matching model of the labor market that uses intrafirm bargaining.

The model is populated by large firms who face matching frictions to hire workers and training costs to train workers. Training is assumed to be purely specific, financed by the firm, and given to workers who have already been hired by the firm. Workers are firstly hired and then (perhaps) trained according to the firm's decision. In this context, there are two types of workers in the firms: the trained and the untrained. To analyze the consequences of intrafirm bargaining, the model is solved under two alternative assumptions with regard to the wage bargaining process ${ }^{3}$.

- Under the first assumption, the wage bargaining process is treated as external to firms: a firm does not take into account the consequences of its hiring and training decisions for the wages bargained with its workers. This bargaining process is referred to an extrafirm bargaining process.

- Under the second assumption, the wage bargaining process is treated as internal to firms: a firm takes into account the consequences of its hiring and training decisions for the wages bargained with its workers. This bargaining process is referred to an intrafirm bargaining process.

The first assumption leads to inefficient training and hiring decisions by firms, for two reasons. Firstly, when a firm has paid the fixed cost of training, the worker can capture a share of the surplus, without having paid for it. This is the well-known phenomenon of hold-up, which arises in the context of imperfect labor markets and fixed costs. Secondly, and following from the first point, if trained workers can hold up the firm, untrained workers will accept, in compensation for potential training that is accessible only following employment, wages that are too low. This second problem respect to the mass vacant jobs (respectively unemployed workers).

${ }^{3}$ Krause and Lubik (2007) proceed similarly to assess the importance of intrafirm bargaining for the behavior of the matching model with respect to the business cycle. 
worsens the inefficiency of training decision. Firms have insufficient motivation to invest in training and prefer to keep too many workers untrained, whose wages are excessively low compared with the wages of trained workers. The consequences for employment are ambiguous. There can be over or under-employment. However, there can generally no efficient employment even if the condition of Hosios (1990) applies.

I show that the firms' decisions become efficient under the second assumption. By using the intrafirm bargaining process on wages, firms take into account the negative impact of training on the wages of untrained workers. Training workers not only improves the efficiency of production; it also reduces the wage of untrained workers. Compared with the case of extrafirm bargaining, taking this payoff into account leads firms to increase their hiring effort up to the optimal level. The condition of Hosios (1990) is then sufficient to guarantee the efficiency of hiring. It is worth mentioning that competitive efficiency is achieved with wage inequality between trained and untrained workers even if training is specific and paid only by the firms.

The remainder of the article is organized as follows. Section 2 describes the processes of matching, training, and production. Section 3 presents the optimal equilibrium as the solution of the social planner's problem. The competitive equilibrium is introduced in Section 4 and its efficiency properties analyzed in section 5. Section 6 concludes.

\section{Matching, training, and production}

The final good $y$ is produced with two labor inputs: that of untrained workers, $u$, and that of trained workers, $t$, according to $y=f(u, t)$, where the production technology $f(\cdot, \cdot)$ is continuous, twice differentiable, increasing, and concave in both arguments. Training is specific to firms, which means that all new hired workers are untrained because firms cannot hire trained workers. In addition, I assume that firms cannot simultaneously hire and train a worker. Training must follow hiring. 
The law of motion of the mass of untrained workers is

$$
u^{\prime}=(1-\psi) u-\alpha u+\mu(v, s)
$$

where $u^{\prime}$ is the next period mass of untrained workers, $\psi$ is the exogenous rate of job destruction, $(\alpha u)$ is the flow of workers trained with $\alpha$ the training rate, and $\mu(v, s)$ is the flow of new hires. This flow is the outcome of the matching process on the labor market and given by the matching technology $\mu(v, s)$, where $v$ is the vacant job supply by firms and $s=(1-u-t)$ denotes the mass of unemployed workers (the population size is normalized to the unity). There is no on-the-job search; only unemployed workers can search for a job. The matching technology $\mu(v, s)$ is continuous, twice differentiable, increasing, and concave in both arguments. The matching probabilities are denoted by $p(\theta)$ for workers and $q(\theta)$ for vacancies, with $\theta=v / s$ being the labor market tightness.

The law of motion of the mass of trained workers is

$$
t^{\prime}=(1-\psi) t+\alpha u
$$

where $t^{\prime}$ is the next period mass of trained workers, $(1-\psi)$ is the survival rate of jobs to the obsolescence process, and $(\alpha u)$ the flow of new trained workers. The final good market equilibrium is

$$
y+s b=c+h \alpha u+d v
$$

where $y$ is the final good production by firms, $b$ is the home production of final good per unemployed worker, $c$ is the consumption, $(h \alpha u)$ the amount spent on training (with $h$ the training cost per worker), and $d v$ the amount spent on searching the labor market (with $d$ the per period search cost for a vacancy).

Lemma 1 Any steady-state equilibrium satisfies the three following steady-state constraints

$$
\begin{gathered}
u+t=p(\theta) /[\psi+p(\theta)] \\
\psi t=\alpha u
\end{gathered}
$$




$$
f(u, t)+(1-t-u) b=c+h \alpha u+d \theta(1-t-u)
$$

which are deduced from equations (1), (2), and (3), respectively.

Equation (4) determines the employment rate in the economy $(u+t)$ as a function of the hiring rate, $p(\theta)$, and the job destruction rate, $\psi$. To ensure the constancy of the mass of trained workers, the flows of trained workers displaced $(\psi t)$ and of untrained workers trained $(\alpha u)$ are equal; see Equation (5). The ratio of trained workers to untrained workers $(t / u)$ is then equal to the ratio of the training rate to the job destruction rate $(\alpha / \psi)$. Equation (6) re-expresses the market equilibrium condition for the final good given by Equation (3) with the masses of workers, the consumption, the training rate, and the labor market tightness.

\section{The social optimum}

The efficient allocation is the outcome of the the social planner's program. Households' preferences are defined by the subjective discount rate, $\beta$, and a linear utility function with respect to the consumption. Then, the maximization problem of the social planner is characterized by the following value function:

$$
\begin{aligned}
\mathcal{P}(u, t)= & \max _{\left\{v, \alpha, u^{\prime}, t^{\prime}\right\}}\left\{f(u, t)+(1-t-u) b-h \alpha u-d v+\beta \mathcal{P}\left(u^{\prime}, t^{\prime}\right)\right\} \\
& -\lambda^{u}\left[u^{\prime}-(1-\psi) u+\alpha u-\mu(v, 1-u-t)\right]-\lambda^{t}\left[t^{\prime}-(1-\psi) t-\alpha u\right]
\end{aligned}
$$

with $t_{0}>0$ and $u_{0}>0$ the initial conditions of the state variables. The first-order condition with respect to the mass of vacant jobs, $v$, gives

$$
d=\mu_{1}(v, 1-u-t) \times \lambda^{u}
$$

the marginal cost of a vacancy, $d$, is equal to its marginal contribution in the matching process, $\mu_{1}(v, s)$, times the value of the marginal untrained worker, $\lambda^{u}$. The first-order condition with respect 
to the training effort, $\alpha$, is

$$
h=\lambda^{t}-\lambda^{u}
$$

the marginal cost of training, $h$, is equal to the difference between the values of the marginal trained worker and the marginal untrained worker, $\lambda^{t}-\lambda^{u}$.

The first-order condition with respect to the next period mass of untrained workers, $u^{\prime}$, is

$$
\lambda^{u}=\beta \mathcal{P}_{1}\left(u^{\prime}, t^{\prime}\right)
$$

The envelop condition, with Equation (8), gives

$$
\frac{d}{\mu_{1}(v, 1-u-t)}=\beta\left\{f_{1}\left(u^{\prime}, t^{\prime}\right)-b-d \frac{\mu_{2}\left(v^{\prime}, 1-u^{\prime}-t^{\prime}\right)}{\mu_{1}\left(v^{\prime}, 1-u^{\prime}-t^{\prime}\right)}+(1-\psi) \frac{d}{\mu_{1}\left(v^{\prime}, 1-u^{\prime}-t^{\prime}\right)}\right\}
$$

The RHS of (11) is the contribution of the marginal untrained worker to the tomorrow value function. This is composed of three terms: $(i)$ the differential of the marginal productivity of untrained workers in the production sector, $f_{1}\left(u^{\prime}, t^{\prime}\right)$, and of the constant marginal productivity of these workers in the home production sector, $b$; $(i i)$ the search cost, $d$, multiplied by the ratio of the marginal productivity in the matching function of unemployed workers, $\mu_{2}(\cdot)$, and of vacant jobs, $\mu_{1}(\cdot)$; and $(i i i)$ the survival rate of job, $(1-\psi)$, times the contribution of the marginal untrained worker to the value function.

The first-order condition with respect to the mass of trained workers, $t^{\prime}$, is

$$
\lambda^{t}=\beta \mathcal{P}_{1}\left(u^{\prime}, t^{\prime}\right)
$$

The envelop condition, with Equation (9), gives

$$
\frac{d}{\mu_{1}(v, 1-u-t)}+h=\beta\left\{f_{2}\left(u^{\prime}, t^{\prime}\right)-b-d \frac{\mu_{2}\left(v^{\prime}, 1-u^{\prime}-t^{\prime}\right)}{\mu_{1}\left(v^{\prime}, 1-u^{\prime}-t^{\prime}\right)}+(1-\psi)\left(\frac{d}{\mu_{1}\left(v^{\prime}, 1-u^{\prime}-t^{\prime}\right)}+h\right)\right\}
$$

The differences between Equations (13) and (11) yield (i) the definition of the marginal productivity of workers, $f_{2}\left(u^{\prime}, t^{\prime}\right)$ instead of $f_{1}\left(u^{\prime}, t^{\prime}\right)$, and (ii) the definition of the marginal contribution of workers 
to the current value function, $\left(d / \mu_{1}(\cdot)+h\right)$ instead of $d / \mu_{1}(\cdot)$. The marginal productivity of trained workers is higher than for untrained workers, but these workers have an additional cost, $h$.

Lemma 2 The social planner's rules for training and hiring are in the steady state:

$$
\begin{aligned}
\beta^{*} \frac{d}{\mu_{1}(v, s)} & =f_{1}(u, t)-b-d \frac{\mu_{2}(v, s)}{\mu_{1}(v, s)} \\
\beta^{*} h & =f_{2}(u, t)-f_{1}(u, t)
\end{aligned}
$$

where $\beta^{*}=\left(\beta^{-1}-(1-\psi)\right)$.

These two Equations (14) and (15) are deduced from Equations (11) and (13). Training and hiring costs are discounted by the rate $\beta^{*}$, which combines the intertemporal discounting of household $(\beta)$ and the survival rate of jobs $(1-\psi)$. The social planner equalizes the marginal cost of training (discounted by $\beta^{*}$ ) to the net surplus of training measured by the difference between the marginal productivities of trained and untrained workers.

Definition 1 The steady-state efficient allocation is defined by the set of endogenous variables $\widehat{\mathcal{Y}}=$ $\{\widehat{u}, \widehat{t}, \widehat{\theta}, \widehat{\alpha}, \widehat{c}\}$ that solve the equilibrium constraints (4)-(5)-(6) and the rules of hiring and training (14)-(15).

\section{The competitive economy}

To define the competitive economy, I first introduce the firms' problem and then solve the wage bargaining process.

\subsection{The Firm's Value Function}

At each period, the representative firm bargains the wages with all the workers in the firm, decides the number of vacancies posted on the labor market, and chooses the fraction of untrained workers 
to train. The bargained wages are functions of the firm's masses of workers and of the firm's training rate: $w^{u}(u, t, \alpha)$ for untrained workers and $w^{t}(u, t, \alpha)$ for trained workers. Other variables, such as the unemployed hiring rate, influence the wages, but they do not directly depend on the firm's decision and are consequently not introduced in the bargained wage functions.

The maximization problem of the representative firm is characterized by the following value function:

$$
\begin{aligned}
\mathcal{F}(u, t)= & \max _{\left\{v, \alpha, u^{\prime}, t^{\prime}\right\}}\left\{f(u, t)-w^{u}(u, t, \alpha) u-w^{t}(u, t, \alpha) t-h \alpha u-d v+\beta \mathcal{F}\left(u^{\prime}, t^{\prime}\right)\right\} \\
& -\zeta^{u}\left[u^{\prime}-(1-\psi) u+\alpha u-q(\theta) v\right]-\zeta^{t}\left[t^{\prime}-(1-\psi) t-\alpha u\right]
\end{aligned}
$$

with $t_{0}>0$ and $u_{0}>0$ the initial conditions of the state variables. The first-order condition with respect to the mass of vacant jobs $v$ gives

$$
d=q(\theta) \times \zeta^{u}
$$

the marginal cost of a vacancy, $d$, is equal to its matching probability, $q(\theta)$, times the value of the marginal untrained worker, $\zeta^{u}$. The first-order condition with respect to the hiring rate $\alpha$ is

$$
h=\zeta^{t}-\zeta^{u}-\left[w_{3}^{u}(u, t, \alpha) u+w_{3}^{t}(u, t, \alpha) t\right] / u
$$

the marginal cost of training, $h$, is equal to the difference between the values of the marginal trained worker and the marginal untrained worker, $\left(\zeta^{t}-\zeta^{u}\right)$, less the adjustment of wages in the firm weighted by the masses of workers, that is, $w_{3}^{x}(u, t, \alpha) x$ for $x=u, t$.

The values of the worker for the firm are given by

$$
\begin{aligned}
\mathcal{F}_{1}(u, t)= & {\left[f_{1}(u, t)-w^{u}(u, t, \alpha)\right]-\left[w_{1}^{u}(u, t, \alpha) u+w_{1}^{t}(u, t, \alpha) t\right]+(1-\psi) \zeta^{u} } \\
& +\alpha\left(\zeta^{t}-\zeta^{u}-h\right)
\end{aligned}
$$

for an untrained worker and by

$$
\mathcal{F}_{2}(u, t)=\left[f_{2}(u, t)-w^{t}(u, t, \alpha)\right]-\left[w_{2}^{u}(u, t, \alpha) u+w_{2}^{t}(u, t, \alpha) t\right]+(1-\psi) \zeta^{t}
$$


for a trained worker. The two functions are composed of similar elements. The first term in brackets is the difference between the marginal productivity of the worker and his wage. The second term in brackets accounts for the effect of the marginal worker on the bargaining wage functions weighted by the masses of workers. The third term is the discount value of the marginal worker, which survives to the exogenous destruction process. The probability that the job is not destroyed is $(1-\psi)$ and the firm conserves the value of the marginal worker. Finally, there is an additional term that is specific to the untrained worker. The probability that the worker is trained and the firm get the net payoff of training is $\alpha$ in Equation (19). This value is equal to the value of the marginal trained worker $\left(\zeta^{t}\right)$, less the value of the marginal untrained worker $\left(\zeta^{u}\right)$, and less the training cost $(h)$.

The first-order conditions with respect to the state variables $u^{\prime}$ and $t^{\prime}$ are

$$
\begin{aligned}
\zeta^{u} & =\beta \mathcal{F}_{1}\left(u^{\prime}, t^{\prime}\right) \\
\zeta^{t} & =\beta \mathcal{F}_{2}\left(u^{\prime}, t^{\prime}\right)
\end{aligned}
$$

where the expression for $\mathcal{F}_{1}\left(u^{\prime}, t^{\prime}\right)$ and $\mathcal{F}_{2}\left(u^{\prime}, t^{\prime}\right)$ are given by (19) and (20), respectively.

Lemma 3 The competitive firms' rules of training and hiring are at the steady state:

$$
\begin{aligned}
\beta^{*} \frac{d}{q(\theta)}= & f_{1}(u, t)-w^{u}(u, t, \alpha)-\left[w_{1}^{u}(u, t, \alpha) u+w_{1}^{t}(u, t, \alpha) t\right] \\
& +\alpha\left[w_{3}^{u}(u, t, \alpha)+w_{3}^{t}(u, t, \alpha) \frac{t}{u}\right] \\
f_{2}(u, t)-f_{1}(u, t)= & \beta^{*} h+\left[w^{t}(u, t, \alpha)-w^{u}(u, t, \alpha)\right] \\
& +\left[w_{2}^{u}(u, t, \alpha) u+w_{2}^{t}(u, t, \alpha) t\right]-\left[w_{1}^{u}(u, t, \alpha) u+w_{1}^{t}(u, t, \alpha) t\right] \\
& +\left(\alpha+\beta^{*}\right)\left[w_{3}^{u}(u, t, \alpha)+w_{3}^{t}(u, t, \alpha) \frac{t}{u}\right]
\end{aligned}
$$

which are deduced from Equations (19)-(20)-(21)-(22). 


\subsection{The Nash Bargaining Solution}

The Nash bargaining solution assumes that each worker, whatever his training level, behaves as the marginal worker and bargains his wage directly with the firm at each period. The untrained and trained worker wages satisfy the following Nash solutions:

$$
\begin{aligned}
& \eta\left(\mathcal{W}_{u}-\mathcal{U}\right)=(1-\eta) \mathcal{F}_{1}(u, t) \\
& \eta\left(\mathcal{W}_{t}-\mathcal{U}\right)=(1-\eta) \mathcal{F}_{2}(u, t)
\end{aligned}
$$

where $\eta$ is the bargaining power of workers, $\mathcal{W}_{u}$ (respectively $\mathcal{W}_{t}$ ) is the value function of being matched for an untrained (respectively trained) worker and $\mathcal{U}$ is the value function of being unemployed. These value functions are defined as follows:

$$
\begin{gathered}
\mathcal{W}_{u}=w^{u}(u, t, \alpha)+(1-\psi-\alpha) \beta \mathcal{W}_{u}^{\prime}+\alpha \beta \mathcal{W}_{t}^{\prime}+\psi \beta \mathcal{U}^{\prime} \\
\mathcal{W}_{t}=w^{t}(u, t, \alpha)+(1-\psi) \beta \mathcal{W}_{t}^{\prime}+\psi \beta \mathcal{U}^{\prime} \\
\mathcal{U}=b+p(\theta) \beta \mathcal{W}_{u}^{\prime}+(1-p(\theta)) \beta \mathcal{U}^{\prime}
\end{gathered}
$$

An untrained worker earns the wage $w^{u}(u, t, \alpha)$ and keeps his job with probability $(1-\psi-\alpha)$; in this case, he gets $\beta \mathcal{W}_{u}^{\prime}$. The probability that this worker is trained and then gets the discounted value of being trained and matched at the next period, $\beta \mathcal{W}_{t}^{\prime}$, is $\alpha$. Finally, the probability that the job is destroyed and the worker gets the discounted value of being unmatched at the next period, $\beta \mathcal{U}^{\prime}$, is $\psi$. A trained worker earns the wage $w^{t}(u, t, \alpha)$ and keeps his job with probability $(1-\psi)$; otherwise, the job is destroyed and the worker returns to the labor market as unemployed. Unemployed workers earn $b$ as home production and face a probability $p(\theta)$ of matching.

Lemma 4 The equilibrium wage functions solve a two-dimension system of partial derivative equations, given by

$$
w^{u}(u, t, \alpha)+(1-\eta)\left[w_{1}^{u}(u, t, \alpha) u+w_{1}^{t}(u, t, \alpha) t\right]=\eta b+(1-\eta)\left[f_{1}(u, t)+d \theta\right]-(1-\eta) \alpha h
$$




$$
w^{t}(u, t, \alpha)+(1-\eta)\left[w_{2}^{u}(u, t, \alpha) u+w_{2}^{t}(u, t, \alpha) t\right]=\eta b+(1-\eta)\left[f_{2}(u, t)+d \theta\right]
$$

The wage premium for trained workers is

$$
\begin{aligned}
w^{t}(u, t, \alpha)-w^{u}(u, t, \alpha)= & (1-\eta)\left[f_{2}(u, t)-f_{1}(u, t)+\alpha h\right] \\
& +(1-\eta)\left[w_{1}^{u}(u, t, \alpha) u+w_{1}^{t}(u, t, \alpha) t-w_{2}^{u}(u, t, \alpha) u-w_{2}^{t}(u, t, \alpha) t\right]
\end{aligned}
$$

See appendix A.1 for details of the calculus.

\section{Efficiency of the competitive equilibrium}

The efficiency of the competitive equilibrium is solved under several assumptions that reduce the variety of distortions in the economy. I first give a formal definition of the competitive equilibrium.

Definition 2 The steady-state competitive allocation is defined by the set of endogenous variables $\widetilde{\mathcal{Y}}=\{\widetilde{u}, \widetilde{t}, \widetilde{\theta}, \widetilde{\alpha}, \widetilde{c}\}$ and the wage functions $w^{u}(\widetilde{u}, \widetilde{t}, \widetilde{\alpha})$ and $w^{t}(\widetilde{u}, \widetilde{t}, \widetilde{\alpha})$ that solve the equilibrium constraints (4)-(5)-(6), the firm's rules for training and hiring (23)-(24), and the Nash Bargaining solutions for the wages (30)- (31).

\subsection{Assumptions}

The analysis of the efficiency of the competitive equilibrium is done under the following three assumptions.

A1 The matching function is a Cobb-Douglas technology with constant return to scale: $\mu(v, s)=$ $\bar{\mu} v^{\chi} s^{1-\chi}$, with $0<\chi<1, \bar{\mu}>0, \mu_{1}(v, s)=\chi \bar{\mu} \theta^{\chi-1}$, and $\mu_{2}(v, s)=(1-\chi) \bar{\mu} \theta^{\chi}$.

A2 The bargaining power of workers is equal to the elasticity parameter of the matching technology with respect to unemployed workers $\eta=\chi$. 
A3 The production function is a Cobb-Douglas technology with constant return to scale: $f(u, t)=$ $u^{1-\sigma} t^{\sigma}$, with $0<\sigma<1, f_{1}(u, t)=(1-\sigma)(t / u)^{\sigma}$, and $f_{2}(u, t)=\sigma(t / u)^{\sigma-1}$

These assumptions rule out several sources of inefficiency to focus on the issue of firm-specific training in large firms. Assumption 1 rules out the possibilities of multiple equilibria or complex dynamics induced by increasing returns to scale in the matching function; see Mortensen (1999). Assumptions 1 and 2 ensure that externalities in the matching process are internalized in the wage bargaining process, as has been well known following Hosios (1990) and Pissarides (2000). Assumption 3 rules out the case of strategic overemployment by firms that was pointed out by Smith (1999) and Cahuc et al. (2008), when returns to scale in the production function are non-constant.

Under Assumptions A1-A3, some key equilibrium relations can be simplified as follows. The wage functions $w^{u}(u, t, \alpha)$ and $w^{t}(u, t, \alpha)$ solutions of (30) and (31) are now

$$
\begin{gathered}
w^{u}(u, t, \alpha)=\eta b+(1-\eta) d \theta+(1-\eta)(1-\sigma)(\widehat{\alpha} / \psi)^{\sigma}-(1-\eta) \alpha h \\
w^{t}(u, t, \alpha)=\eta b+(1-\eta) d \theta+(1-\eta) \sigma \psi^{\sigma-1} \widehat{\alpha}^{\sigma-1}
\end{gathered}
$$

Both wage functions have the same two first terms and are increasing with the home production's productivity $(b)$ and the labor market tightness $(\theta)$. The ratio of trained workers to untrained workers (equal to $\alpha / \psi$ ) has the following consequences for wages. Increasing the training effort $(\alpha)$ diminishes the marginal productivity of trained workers (and then their wage $w^{t}(u, t, \alpha)$ ), whereas it increases the marginal productivity of untrained workers (and then their wage $w^{u}(u, t, \alpha)$ ). For untrained workers, there is an additional term, $-(1-\eta) \alpha h$. Being matched gives untrained workers an opportunity to access a training program. This opportunity weakens the threat point of workers and lowers the wage.

The optimal training rate $\widehat{\alpha}$ and the labor market tightness $\widehat{\theta}$ solutions of (14)-(15) solve

$$
\sigma(\widehat{\alpha} / \psi)^{\sigma-1}-(1-\sigma)(\widehat{\alpha} / \psi)^{\sigma}=\beta^{*} h
$$




$$
\beta^{*} \frac{d}{\bar{\mu}} \widehat{\theta}^{1-\chi}=\chi\left[(1-\sigma)(\widehat{\alpha} / \psi)^{\sigma}-b\right]-(1-\chi) d \widehat{\theta}
$$

given $(t / u)=\alpha / \psi$, see Equation (5). Equation (35) gives the implicit expression of $\widehat{\alpha}$ as a function of parameters $\rho_{\alpha}=\left\{\sigma, \psi, \beta^{*}, h\right\}$. Equation (36) gives the implicit expression of $\widehat{\theta}$ as a function of the value $\widehat{\alpha}$ and the parameters $\rho_{\theta}=\left\{\rho_{\alpha}, d, \bar{\mu}, \chi, b\right\}$. The labor market tightness depends positively on the hiring rate, because training improves the marginal productivity of newly hired workers.

\subsection{Wage structure and efficiency}

To analyze the efficiency of hiring and training by competitive firms, I proceed in two steps.

- First, I solve the wage bargaining process, without taking into account the intrafirm dimension of the problem. This corresponds to the extrafirm bargaining process. Each firm neglects the consequences of its hiring and training decisions for the wages bargained inside this firm. The corresponding wages lead to suboptimal hiring and training efforts.

- Afterwards, I solve the complete wage bargaining process, taking into account the intrafirm dimension of the problem. I show that the intrafirm bargaining process solves the problems identified in the first step and leads to firms making efficient hiring and training decisions.

Proposition 1 Without intrafirm bargaining, firms do not hire and train workers efficiently. The competitive training rate is below the optimal training rate and the competitive labor market tightness can be either above or below the optimal value.

Proof. With extrafirm bargaining, the partial derivatives of wage functions with respect to the firm's variable decisions are null: $w_{i}^{u}(u, t, \alpha)=0$ and $w_{i}^{u}(u, t, \alpha)=0$ for $i=1,2,3$, and the firm's rules for training and hiring, which are defined by Equations (23) and (24), become

$$
\beta^{*} \frac{d}{q(\theta)}=f_{1}(u, t)-w^{u}(u, t, \alpha)
$$




$$
f_{2}(u, t)-f_{1}(u, t)=\beta^{*} h+w^{t}(u, t, \alpha)-w^{u}(u, t, \alpha)
$$

where the wage $w^{u}(u, t, \alpha)$ is given by Equation (33) and the wage premium for trained workers, deduced directly from Equation (32), is

$$
w^{t}(u, t, \alpha)-w^{u}(u, t, \alpha)=(1-\eta)\left[\alpha h+f_{2}(u, t)-f_{1}(u, t)\right]
$$

Let $\bar{x}$ denote the equilibrium value of $x$ in the competitive economy without intrafirm bargaining. The competitive training rate $\bar{\alpha}$ and labor market tightness $\bar{\theta}$ are the solutions of

$$
\begin{gathered}
\frac{(1-\eta) \bar{\alpha} h+\beta^{*} h}{\eta}=\sigma(\bar{\alpha} / \psi)^{\sigma-1}-(1-\sigma)(\bar{\alpha} / \psi)^{\sigma} \\
\beta^{*} \frac{d}{\bar{\mu}} \bar{\theta}^{1-\chi}+(1-\eta) d \bar{\theta}=\eta\left[(1-\sigma)(\bar{\alpha} / \psi)^{\sigma}-b\right]+(1-\eta) \bar{\alpha} h
\end{gathered}
$$

The condition $\bar{\alpha}<\widehat{\alpha}$ of insufficient competitive training is always satisfied, because $\bar{\alpha}>-\beta^{*}$. The condition of excessive competitive hiring $\bar{\theta}>\widehat{\theta}$ requires

$$
(1-\eta) \bar{\alpha} h>\eta(1-\sigma) \psi^{-\sigma}\left(\widehat{\alpha}^{\sigma}-\bar{\alpha}^{\sigma}\right)
$$

With extrafirm bargaining, two distortions create inefficiency in the competitive economy. The first distortion is the presence of the term $(1-\eta) \alpha h$ in Equation (41), which is absent in its counterpart in the planned economy, Equation (36). Being matched gives untrained workers an opportunity to access a training program. This opportunity weakens the threat point of workers and lowers the wage. Due to the fact that untrained workers receive low wages, firms hire too many workers (for a fixed value of the untrained marginal productivity $\left.f_{1}(u, t)\right)$.

The second distortion is the evaluation of the cost of training $h$ by the firms in the competitive economy (see Equation (40)) and $\chi h$ by the social planner (see Equation (35)). For a fixed value of the labor market tightness, $\theta$, this distortion leads to insufficient training in the competitive economy. The trained workers appropriate a share of the marginal productivity of trained workers, which is 
higher than the marginal productivity of untrained workers. This corresponds to the well-known hold-up phenomenon, which is induced here by the specific training costs. This distortion is the second component of the wage premium defined in (39).

Proposition 2 With intrafirm bargaining, firms hire and train workers efficiently.

Proof. Let $\widetilde{x}$ denote the equilibrium value of $x$ in the competitive economy without intrafirm bargaining. The wage functions $w^{u}(\widetilde{u}, \widetilde{t}, \widetilde{\alpha})$ and $w^{t}(\widetilde{u}, \widetilde{t}, \widetilde{\alpha})$ given by (33) and (34) imply

$$
\begin{aligned}
& w_{3}^{u}(\widetilde{u}, \widetilde{t}, \widetilde{\alpha})=-(1-\eta) h \\
& w_{3}^{t}(\widetilde{u}, \widetilde{t}, \widetilde{\alpha})=0
\end{aligned}
$$

The firm's rule for training that is defined by Equation (24) is then

$$
\sigma(\widetilde{\alpha} / \psi)^{\sigma-1}-(1-\sigma)(\widetilde{\alpha} / \psi)^{\sigma}=\beta^{*} h+w^{t}(\widetilde{u}, \widetilde{t}, \widetilde{\alpha})-w^{u}(\widetilde{u}, \widetilde{t}, \widetilde{\alpha})-\left(\widetilde{\alpha}+\beta^{*}\right)(1-\eta) h
$$

Given the wage premium, which is still given by Equation (32), Equation (44) becomes

$\sigma(\widetilde{\alpha} / \psi)^{\sigma-1}-(1-\sigma)(\widetilde{\alpha} / \psi)^{\sigma}=\beta^{*} h+(1-\eta)\left[\widetilde{\alpha} h+\sigma(\widetilde{\alpha} / \psi)^{\sigma-1}-(1-\sigma)(\widetilde{\alpha} / \psi)^{\sigma}\right]-\left(\alpha+\beta^{*}\right)(1-\eta) h=\beta^{*} h$

which is equivalent to the optimal rule for training defined by Equation (35). The firm's rule for hiring, defined by Equations (23), is then

$$
\begin{aligned}
\beta^{*} \frac{d}{\bar{\mu}} \widetilde{\theta}^{1-\chi} & =(1-\sigma)(\widetilde{\alpha} / \psi)^{\sigma}-w^{u}(\widetilde{u}, \widetilde{t}, \widetilde{\alpha})-\widetilde{a}(1-\eta) h \\
& =\eta\left[(1-\sigma)(\widetilde{\alpha} / \psi)^{\sigma}-b\right]-(1-\eta) d \theta
\end{aligned}
$$

which is equivalent to the optimal rule for training defined by Equation (36), because $\eta=\chi$ (see assumption A2).

As the training rate $\alpha$ increases, the wage of untrained workers decreases. However, the increase in $\alpha$ has no direct effect on the wage of trained workers. An increase in $\alpha$ increases the probability 
of being trained in the firm; consequently, the threat point of untrained workers is weaker and their wages lower. Intrafirm bargaining creates a gain to the firm that is derived from specific training decisions, which modifies the training and hiring decisions. This wage gain is equal to $-(1-\eta) h$, see Equation (42), and appears firstly in the RHS term of Equation (44). This term measures the total cost of training, which is reduced as a result of the wage gain of training. Remember that without intrafirm bargaining, training is insufficient. By reducing the total cost of training, the intrafirm bargaining stimulates training and then improves the efficiency of the labor market. It is worth mentioning that the term $(1-\eta) h$ appears in the definition of the wage premium given by Equation (32). Equation (45) shows how these terms nullify each other, thereby leading to an efficient competitive training rule.

The wage gain of training appears for a second time in the RHS term of Equation (46). This term measures the total payoff of hiring, which is equal to the expected value of an untrained worker. With intrafirm bargaining, the marginal untrained worker has a specific opportunity cost, which is equal to the fall in untrained wage that the firm would obtain if it were to train the worker. This opportunity cost diminishes the value of the marginal untrained for the firm and then improves the efficiency of hiring. Indeed, without intrafirm bargaining, untrained wages are too low. Here, given that the opportunity cost is taken into account by firms, hiring is efficient.

In sum, the intrafirm bargaining mechanism corrects the two distortions that were identified as occurring when the bargaining for wages is extrafirm. The efficiency of hiring and training decisions is reached when there is a wage inequality between trained and untrained workers. Note that wage inequality is not a generally necessary condition of efficiency. However, it is a necessary condition in the specific context of a decentralized, repeated, and individual wage bargaining process. I show in appendix A.2 that there exists an unique wage level for all workers that would lead to efficiency if this wage was imposed exogenously on competitive firms. However, this wage is not consistent with a Nash bargaining process, except when workers are assumed not to take into account the increase 
of their marginal productivity after they are trained.

\section{Conclusion}

I have developed a model to assess the consequences of intrafirm bargaining on decisions regarding hiring and training and the efficiency of the labor market. The imperfections in the labor market are potentially responsible for inefficiency in the labor market, because the trained workers are able to hold up firms to obtain higher wages and the untrained workers accept low wages in return for potential training. Without intrafirm bargaining, firms underinvest in training and may either underor over-hire workers. With intrafirm bargaining, firms internalize the specific benefit from training through the fall in wages of untrained workers. This benefit leads firms to hire and train workers efficiently. This conclusion shows the importance of the internal dimension of the firms' choices for assessing the consequences of imperfections in the labor market. 


\section{References}

Acemoglu, D. (1997). Training and Innovation in an Imperfect Labour Market. Review of Economic Studies, 64(3), 445-464.

Acemoglu, D., \& Pischke, J. (1999). Beyond Becker: Training in Imperfect Labour Markets. Economic Journal, 109(453), F112-42.

Boone, J., \& de Mooij, R. (2003). Tax Policy in a Matching Model with Training. Oxford Economic Papers, 55(1), 121-147.

Cahuc, P., \& Wasmer, E. (2001). Does Intrafirm Bargaining Matter in the Large Firm's Matching Model? Macroeconomic Dynamics, 5, 742-747.

Cahuc, P., Marque, F., \& Wasmer, E. (2008). A Theory of Wages and Labor Demand with Intra-firm Bargaining and Matching Frictions. International Economic Review, 49(3), 943-972.

Cheron, A. (2005). Efficient v.s. Equilibrium Unemployment with Match-Specific Costs. Economics Letters, 88(2), 176-183.

Cheron, A., Hairault, J., \& Langot, F. (2008). A Quantitative Evaluation of Payroll Tax Subsidies

for Low-Wage Workers: An Equilibrium Search Approach. Journal of Public Economics, 92(3-4), 817-843.

Ericson, T. (2005). Personnel training: a theoretical and empirical review. Institute for Labour Market Policy Evaluation Working Paper 2005:1.

Hosios, A. (1990). On the Efficiency of Matching and Related Models of Search and Unemployment. Review of Economic Studies, 57(2), 279-298.

Hungerbuhler, M. (2007). Tax Progression and Training in a Matching Framework. Labour Economics, 14(2), 185-200.

Krause, M., \& Lubik, T. (2007). Does intra-firm bargaining matter for business cycle dynamics?. 
Deutsche Bank Discussion Paper, Series 1: Economic Studies No 17/2007.

Malcomson, J. (1997). Contracts, Hold-Up, and Labor Markets. Journal of Economic Literature, 35(4), 1916-1957.

Moen, E., \& Rosen, A. (2004). Does Poaching Distort Training?. Review of Economic Studies, 71(4), 1143-1162.

Mortensen, D. (1999). Equilibrium Unemployment Dynamics. International Economic Review, 40(4), 889-914.

Mortensen, D. (2000). Equilibrium Unemployment with Wage Posting: Burdett-Mortensen Meet Pissarides. in H. Bunzel, B.J. Christiansen, P. Jensen, N.M. Kiefer and D.T. Mortensen, eds., Panel Data and Structural Labor Market Models, Amsterdam: Elsevier, pp. 281-292.

Mortensen, D. (2009). Wage Dispersion in the Search and Matching Model with Intra-Firm Bargaining, NBER Working Paper No. 15033.

Pissarides, C. (2000). Equilibrium unemployment theory (Second edition). MIT Press.

Rosholm, M., \& Svarer, M. (2004). Endogenous Wage Dispersion in a Search-Matching Model. Labour Economics, 11(5), 623-645.

Shintoyo, N. (2008). Creation of Jobs and Firm-Sponsored Training in a Matching Model of Unemployment. Journal of Economics (Zeitschrift fur Nationalokonomie), 93(2), 145-176.

Smith, E. (1999). Search, Concave Production, and Optimal Firm Size. Review of Economic Dynamics, 2(2), 456-471.

Stole, L., \& Zwiebel, J. (1996). Intra-firm Bargaining under Non-binding Contracts. Review of Economic Studies, 63(3), 375-410.

Stole, L., \& Zwiebel, J. (1996). Organizational Design and Technology Choice under Intrafirm Bargaining. American Economic Review, 86(1), 195-222. 


\section{A Appendix}

\section{A.1 The wage functions}

This appendix provides details of the calculus that are useful for obtaining the key equations that are reported for the wage functions. The surpluses for matched workers are

$$
\begin{aligned}
& \mathcal{W}_{u}-\mathcal{U}=w^{u}(u, t, \alpha)-b+(1-\psi-\alpha-p)\left(\beta \mathcal{W}_{u}^{\prime}-\beta \mathcal{U}^{\prime}\right)+\alpha\left(\beta \mathcal{W}_{t}^{\prime}-\beta \mathcal{U}^{\prime}\right) \\
& \mathcal{W}_{t}-\mathcal{U}=w^{t}(u, t, \alpha)-b+(1-\psi)\left(\beta \mathcal{W}_{t}^{\prime}-\beta \mathcal{U}^{\prime}\right)-p\left(\beta \mathcal{W}_{u}^{\prime}-\beta \mathcal{U}^{\prime}\right)
\end{aligned}
$$

for untrained and trained workers, respectively. To solve the Nash Bargaining program, the FOCs' firm (21)-(22) are used to express the expected surplus of workers as function of the contribution of marginal workers to the firm's value function

$$
\begin{aligned}
& \beta\left(\mathcal{W}_{u}^{\prime}-\mathcal{U}^{\prime}\right)=\left(\frac{1-\eta}{\eta}\right) \beta \mathcal{F}_{1}\left(u^{\prime}, t^{\prime}\right)=\left(\frac{1-\eta}{\eta}\right) \zeta^{u} \\
& \beta\left(\mathcal{W}_{t}^{\prime}-\mathcal{U}^{\prime}\right)=\left(\frac{1-\eta}{\eta}\right) \beta \mathcal{F}_{2}\left(u^{\prime}, t^{\prime}\right)=\left(\frac{1-\eta}{\eta}\right) \zeta^{t}
\end{aligned}
$$

Then, the surplus (A.1)-(A.2) become

$$
\begin{aligned}
& \mathcal{W}_{u}-\mathcal{U}=w^{u}(u, t, \alpha)-b+(1-\psi-\alpha-p)\left(\frac{1-\eta}{\eta}\right) \zeta^{u}+\alpha\left(\frac{1-\eta}{\eta}\right) \zeta^{t} \\
& \mathcal{W}_{t}-\mathcal{U}=w^{t}(u, t, \alpha)-b+(1-\psi)\left(\frac{1-\eta}{\eta}\right) \zeta^{t}-p\left(\frac{1-\eta}{\eta}\right) \zeta^{u}
\end{aligned}
$$

For $f(u, t)=u^{\sigma_{u}} t^{\sigma_{t}}$, the wage functions solution of (30) and (31) are

$$
\begin{aligned}
w^{u}(u, t, \alpha) & =\eta b+(1-\eta)\left[\frac{\sigma_{u}}{1-(1-\eta)\left(1-\sigma_{u}-\sigma_{t}\right)} u^{\sigma_{u}-1} t^{\sigma_{t}}+d \theta-\alpha h\right] \\
w^{t}(u, t, \alpha) & =\eta b+(1-\eta)\left[\frac{\sigma_{t}}{1-(1-\eta)\left(1-\sigma_{u}-\sigma_{t}\right)} u^{\sigma_{u}} t^{\sigma_{t}-1}+d \theta\right]
\end{aligned}
$$


The first order partial derivatives of the wage functions are

$$
\begin{aligned}
w_{3}^{u}(u, t, \alpha) & =-(1-\eta) h \\
w_{3}^{t}(u, t, \alpha) & =0 \\
w_{1}^{u}(u, t, \alpha) & =(1-\eta) \frac{\sigma_{u}\left(\sigma_{u}-1\right)}{1-(1-\eta)\left(1-\sigma_{u}-\sigma_{t}\right)} u^{\sigma_{u}-2} t^{\sigma_{t}} \\
w_{2}^{u}(u, t, \alpha) & =(1-\eta) \frac{\sigma_{u} \sigma_{t}}{1-(1-\eta)\left(1-\sigma_{u}-\sigma_{t}\right)} u^{\sigma_{u}-1} t^{\sigma_{t}-1} \\
w_{1}^{t}(u, t, \alpha) & =(1-\eta) \frac{\sigma_{t} \sigma_{u}}{1-(1-\eta)\left(1-\sigma_{u}-\sigma_{t}\right)} u^{\sigma_{u}-1} t^{\sigma_{t}-1} \\
w_{2}^{t}(u, t, \alpha) & =(1-\eta) \frac{\sigma_{t}\left(\sigma_{t}-1\right)}{1-(1-\eta)\left(1-\sigma_{u}-\sigma_{t}\right)} u^{\sigma_{u}} t^{\sigma_{t}-2}
\end{aligned}
$$

with

$$
\begin{aligned}
w_{1}^{u}(u, t, \alpha) u+w_{1}^{t}(u, t, \alpha) t & =(1-\eta) \frac{\sigma_{u}\left(\sigma_{u}-1\right)+\sigma_{t} \sigma_{u}}{1-(1-\eta)\left(1-\sigma_{u}-\sigma_{t}\right)} u^{\sigma_{u}-1} t^{\sigma_{t}} \\
w_{2}^{u}(u, t, \alpha) u+w_{2}^{t}(u, t, \alpha) t & =(1-\eta) \frac{\sigma_{u} \sigma_{t}+\sigma_{t}\left(\sigma_{t}-1\right)}{1-(1-\eta)\left(1-\sigma_{u}-\sigma_{t}\right)} u^{\sigma_{u}} t^{\sigma_{t}-1}
\end{aligned}
$$

The assumption A3 $\left(\sigma_{t}=\sigma\right.$ and $\left.\sigma_{u}=1-\sigma\right)$ implies

$$
\sigma_{u}\left(\sigma_{u}-1\right)+\sigma_{t} \sigma_{u}=\sigma_{u} \sigma_{t}+\sigma_{t}\left(\sigma_{t}-1\right)=0
$$

and

$$
\begin{aligned}
& w_{1}^{u}(u, t, \alpha)=-(1-\eta)(1-\sigma) \sigma u^{-\sigma-1} t^{\sigma} \\
& w_{2}^{u}(u, t, \alpha)=(1-\eta)(1-\sigma) \sigma u^{-\sigma-} t^{\sigma-1} \\
& w_{1}^{t}(u, t, \alpha)=(1-\eta)(1-\sigma) \sigma u^{-\sigma} t^{\sigma_{t}-1} \\
& w_{2}^{t}(u, t, \alpha)=-(1-\eta)(1-\sigma) \sigma u^{1-\sigma} t^{\sigma_{t}-2}
\end{aligned}
$$

\section{A.2 Efficiency without wage inequality}

The intrafirm bargaining leads to efficient hiring and training decisions of firms, with wage inequality between trained and untrained workers on the labor market. It is worth mentioning that in the 
context of individual Nash bargaining on wages, the wage premium is a necessary condition of efficiency. The next proposition states that there exists a wage structure without wage inequality that is consistent with efficient decisions of firms, but that cannot be reached by Nash bargaining.

Proposition 3 There exists a structure of wages that ensures the efficiency of hiring and training by competitive firms without a wage premium for trained workers.

Proof. For $w^{t}(u, t, \alpha)=w^{u}(u, t, \alpha)=\chi b+(1-\chi)\left[f_{1}(u, t)+d \theta\right] \equiv w^{\circ}$, the competitive rules for hiring and training (23) and (24) are equivalent to the efficient rules defined by (14) and (15).

Firstly, without wage inequality, the competitive gap in worker marginal productivity defined by Equation (24) is equal to $\beta^{*} h$, which is the value used by the social planner. Consequently, the ratio of trained to untrained workers decided by firms is optimal. Secondly, the wage $w^{\circ}$ ensures the optimality of the hiring policy by firms, defined by Equation (23), because matching externality is exactly internalized in the wage under the condition of Hosios (1990). 